\title{
A FENOMENOLOGIA E O DESAFIO DO NATURALISMO '
}

\author{
Dan Zahavi \\ Fundação Nacional de Investigação da Dinamarca: \\ Centro de Investigação da Subjectividade \\ Departamento de Media, Cognição e Comunicação \\ Universidade de Copenhaga
}

É sempre arriscado fazer grandes declarações sobre o desenvolvimento da Filosofia, mas mesmo assim, se nos fosse pedido para descrever em traços largos a Filosofia do século XX, um traço digno de nota poderia ser o seguinte: embora figuras importantes do início do século, figuras como Frege e Husserl, tenham sido muito explícitos ña sua rejeição do Naturalismo (são ambos conhecidos pela sua rejeição da tentativa de naturalizar as leis da Lógica, i.e., pela sua crítica do Psicologismo), a situação mudou consideravelmente. Hoje em dia muitos filósofos - e não poucos do campo da Filosofia Analítica - subscreveriam alguma forma de Naturalismo. Com efeito, o Naturalismo é visto por muitos como a postura metafísica de base. Quem não defende o Naturalismo, defende por certo alguma forma de dualismo substancialista cartesiano. Assim, se há 20 ou 30 anos nos poderíamos inclinar para caracterizar o desenvolvimento da Filosofia no século XX em termos de uma viragem linguística, uma viragem de uma filosofia da subjectividade para uma filosofia da linguagem, hoje pode ser mais adequado descrever este desenvolvimento em termos de uma viragem do anti-naturalismo para o Naturalismo.

Quais as implicações desta viragem? Tem algumas implicações metafísicas bastante decisivas, ou seja, tem implicações quanto à forma como vemos a relação entre a Filosofia e a ciência positiva. De acordo com algumas leituras, comprometer-se com o Naturalismo mais não faz lo que partir do que é natural (por oposição ao sobrenatural), mas penso que é justo dizer que o uso do termo no discurso actual assinala principalmente uma orientação para

1 Traduzido do inglês por Marisa Mourinhø. 
as ciências naturais. Como disse Sellars, num passo famoso, "na dimensão da descrição e explicação do mundo, a Ciência é a medida de todas as coisas, do que é enquanto é, e do que não é enquanto não é” (Sellars 1963, 173). No entanto, até onde os naturalistas considerariam persuasiva a descrição científica da realidade, um compromisso com o Naturalismo tende a acentuar a ideia de que a Filosofia (incluindo a Fenomenologia) pode dar um contributo distinto e autónomo para o estudo da realidade.

Pode encontrar-se um vívido exemplo desta tensão no campo dos estudos da consciência. Como insiste em dizer Francis Crick, "é inútil tentar resolver os problemas da consciência com argumentos filosóficos gerais: o que faz falta são sugestões de novas experiências que possam trazer alguma luz a estes problemas." (Crick 1995, 19). Com efeito, do ponto de vista de Crick, "o estudo da consciência é um problema científico. [...] Não há justificação para a opinião de que só os filósofos podem lidar com ele." (Crick 1995, 258). De facto, muito pelo contrário, visto que os filósofos "têm apresentado um currículo tão pobre nos últimos dois mil anos que fariam melhor em mostrar alguma modéstia em vez da balofa superioridade que habitualmente ostentam." Com isto não se pretende dizer que os filósofos não possam trazer qualquer contributo, mas têm de "aprender a abandonar as suas teorias de estimação quando as provas científicas as contrariam ou mais não farão do que expor-se ao ridículo." (Crick 1995, 258). Em suma, os filósofos são bem-vindos para se juntarem à empresa comum, mas apenas como associados júnior. Na verdade, suspeita-se que a Filosofia (da mente) na opinião de Crick acabará em último caso por se revelar dispensável. Qualquer contributo que possa dar é apenas propedêutico e acabará por ser substituído por uma explicação científica apropriada.

É duvidoso que todos os filósofos comprometidos com o Naturalismo aceitassem esta linha de raciocínio, mas não há dúvida de que o Naturalismo coloca realmente um desafio à Filosofia. Seguidamente, centrar-me-ei na Fenomenologia. Como deverá a Fenomenologia reagir a este desafio? Que conclusões podemos tirar das recentes propostas para naturalizar a Fenomenologia? Uma avaliação correcta é, no entanto, dificultada pelo facto de o Naturalismo estar longe de ser uma posição unívoca. Irei partir de uma concepção reducionista clássica do Naturalismo, não só porque este era o tipo de posição contra a qual Husserl reagiu originalmente, mas também porque continua a ser uma visão muito disseminada e influente. Se isto redunda ou não, em última análise, numa concepção satisfatória do Naturalismo é uma questão à qual voltaremos mais tarde.

\section{O anti-naturalismo husserliano}

Para começar, recapitulemos, em termos sumários, a natureza e motivação do anti-naturalismo husserliano. No longo ensaio de 1910-11 A Filo- 
sofia como ciência de rigor, Husserl descreve o Naturalismo como uma filosofia fundamentalmente imperfeita (Husserl 1987, 41) e argumenta que ela tem tipicamente dois objectivos distintos: a naturalização da idealidade e normatividade, e a naturalização da consciência (Husserl 1987, 9). Do seu ponto de vista, contudo, ambas as tentativas falham o seu objectivo e ambas são erróneas. A redução naturalista da idealidade conduz ao cepticismo (Husserl 1987, 7, 1984, 47). Este era, na verdade, um dos principais argumentos de Husserl na sua famosa luta contra o psicologismo nas Investigações Lógicas. Quanto à crítica de Husserl à tentativa de naturalizar a consciência, ele põe explicitamente em contraste a sua própria fenomenologia da consciência com uma explicação da consciência do âmbito das ciências naturais (Husserl 1987, 17). Ambas as disciplinas investigam a consciência, mas segundo Husserl, fazem-no de formas completamente diferentes. E sugerir que a explicação fenomenológica pode ser absorvida, ou reduzida, ou substituída por uma explicação naturalista é para Husserl um perfeito absurdo. Não quer isto dizer que Husserl não respeita as ciências naturais, mas como ele disse num passo famoso de Ideias I, "Quando são realmente as ciências naturais que falam, ouvimos com prazer e como discípulos. Mas nem sempre são as ciências naturais que falam quando falam os cientistas naturais; e certamente que não o são quando eles estão a falar de 'Filosofia da Natureza' e de 'Epistemologia como uma ciência natural"' (Husserl 1982, 39).

Mas porque se opõe Husserl à tentativa de implementar uma sistemática explicação naturalista da consciência? Porque o Naturalismo é, na sua opinião, incapaz de fazer total justiça à consciência. Não só porque - sob a forma da Psicologia Experimental - perdeu de vista a consciência (subjectiva) (Husserl 1987, 104), mas, mais importante do que isso, porque o Naturalismo trata a consciência como uma entidade real que ocorre no mundo, ou seja, concebe a consciência como um objecto no mundo, ao mesmo nível - embora possivelmente mais complexo - que os vulcões, cataratas, cristais de gelo, pepitas de ouro, rododendros ou buracos negros. Mas para Husserl isto é inaceitável, uma vez que (para ele) a consciência é não apenas um objecto no mundo, mas também um sujeito para o mundo, i.e., uma condição necessária de possibilidade para que qualquer entidade possa ser vista como objecto da forma como é e com o significado que tem. Para pôr as coisas noutros termos, para Husserl, a limitação decisiva do Naturalismo é o facto de este ser incapaz de reconhecer a dimensão transcendental da consciência.

Uma forma de interpretar a revolucionária viragem copernicana de Kant é vê-la como resultando na noção de que a nossa apreensão cognitiva da realidade é mais do que um mero espelhar de um mundo existente. Aliás, Kant transformou a demanda pré-crítica das mais fundamentais unidades construtoras da realidade numa reflexão sobre que condições deve algo satisfazer para que possa ser considerado "real"; qual é a condição de possibilidade da aparição dos objectos? Com modificações várias, esta ideia foi retomada por Husserl e pelos fenomenólogos seguintes. Na realidade, a razão pela qual 
os fenomenólogos têm enfatizado a importância da perspectiva da primeira pessoa e investigado as estruturas fundamentais da consciência e da ipseidade em grande detalhe não foi por considerarem tal investigação um objectivo em si mesma - se assim fosse, a Fenomenologia teria permanecido uma forma de Psicologia Filosófica ou de Antropologia Filosófica - mas a análise era antes motivada por considerações filosóficas transcendentais.

O Naturalismo distingue-se, habitualmente, por compromissos metodológicos, assim como metafísicos. O compromisso metodológico conduz à ideia de que os critérios justificativos correctos são os que se encontram e que são utilizados pelas ciências naturais. O compromisso metafísico conduz à visão monista segundo a qual existe apenas um tipo de coisas, nomeadamente coisas com propriedades naturais, pelo que tudo o que existe é natural. Em conjunto, estes dois compromissos resultam na ideia de que tudo (incluindo tudo o que se refere à vida humana, como a consciência, a cultura e a história) tem de ser estudado pelos métodos das ciências naturais (cf. Aikin 2006, 318). Aliás, esta concepção está frequentemente ligada a uma defesa explícita do Realismo Metafísico. Uma forma de definir o Realismo Metafísico é vê-lo como sendo guiadó por uma certa concepção do conhecimento. Considera-se que o conhecimento consiste num reflexo fiel de uma realidade independente da mente. É considerado como conhecimento de uma realidade que existe independentemente desse conhecimento, e na verdade independentemente de qualquer pensamento e experiência (Williams 2005, 48). Se queremos conhecer a verdadeira realidade, devemos procurar descrever de que modo o mundo é, independentemente de todas as formas em que se nos apresenta a nós seres humanos, ou seja, devemos procurar uma descrição da qual foram apagados todos os vestígios de nós mesmos. O Realismo Metafísico parte do princípio que a experiência do quotidiano combina traços de subjectividade e objectividade e que se pode chegar a um retrato objectivo daquilo que o mundo é realmente, eliminando o subjectivo. Defende, consequentemente, que há que traçar uma clara distinção entre as propriedades que as coisas têm 'em si mesmas' e as propriedades que são ‘projectadas por nós'. Enquanto que o mundo da aparência, o mundo tal como ele é para nós na nossa vida quotidiana, combina características subjectivas e objectivas, a Ciência captura o mundo objectivo, o mundo tal como ele é em si mesmo.

Esta assunção tem sido questionada pelos fenomenólogos. Eles têm vindo a criticar a sugestão de que a Ciência nos pode proporcionar uma descrição a partir de um ponto de vista de nenhures, como se a Ciência se limitasse a espelhar a forma como a natureza pré-existente e independente da mente se classifica a si própria. Sustentam que um ponto de vista de nenhures é inatingível, tal como negam que seja possível olhar de lado para as nossas experiências, para ver se correspondem à realidade. E isto é assim, não porque tais pontos de vista sejam incrivelmente difíceis de alcançar, mas porque o próprio conceito de tais pontos de vista é absurdo. 
Para a Fenomenologia, a Ciência não é simplesmente uma colecção de proposições justificadas inter-relacionadas de forma sistemática. A Ciência é exercida por alguém; é uma posição teórica específica perante o mundo. Esta posição não caiu do céu; tem os seus pressupostos e origens. A objectividade científica é algo a aspirar, mas depende das observações e experiências de indivíduos; é conhecimento que é partilhado por uma comunidade de sujeitos que experienciam e pressupõe uma triangulação de pontos de vista ou perspectivas. Assim, de acordo com esta concepção, em vez de constituir um óbice ou um obstáculo, a consciência acaba por ser um requisito para a objectividade e a busca do conhecimento científico muito mais importante do que, por exemplo, os microscópios e scanners.

Para Husserl, o Naturalismo toma o seu objecto como garantido, a Natureza. Há a assunção de que a realidade está aí, à espera de ser descoberta e investigada. E o objectivo será então adquirir um conhecimento rigoroso e objectivamente válido deste reino dado. Mas para Husserl esta atitude tem de ser distinguida da atitude propriamente filosófica, que questiona criticamente o fundamento mesmo da experiência e do pensamento científico. (Husserl 1987, 13-14). A Filosofia é uma disciplina que não se limita a contribuir ou a ampliar o âmbito do nosso conhecimento científico, mas antes que investiga a base deste conhecimento e que questiona como é ele possível. O Naturalismo negou a existência de um método filosófico específico, afirmando que a Filosofia deveria empregar o mesmo método que todas as ciências exactas usam, o método científico-natural. Mas para Husserl esta linha de raciocínio apenas revela incompreensão quanto à natureza da Filosofia. A Filosofia tem os seus próprios objectivos e requisitos metodológicos; requisitos que para Husserl estão incorporados na sua noção de redução fenomenológica (Husserl 1984, 238-239). Para Husserl, a redução deve fazer-nos sustentar a diferença radical entre a reflexão filosófica e todas as outras formas de pensamento. Tal como ele escreveu em 1907: “Assim, a 'redução fenomenológica'é simplesmente a exigência de, a todo o momento, se manter no âmbito do sentido da investigação correcta, e não confundir Epistemologia com uma investigação científico-natural (objectivista)." (Husserl 1984, 410). Todas as ciências positivas têm por base um campo de dados tidos como adquiridos ou de evidências que são pressupostas, mas não investigadas, pelas próprias ciências. De forma a tornar esta dimensão acessível, é necessário um novo tipo de investigação que "preceda todo o conhecimento e ciência naturais e aponte numa direcção totalmente diferente em relação às ciências naturais" (Husserl 1984, 176). Esta é, como é evidente, uma das razões pelas quais a atitude fenomenológica tem vindo a ser descrita como uma direcção de pensamento não-natural (Husserl 2001, I. 170). Mas descrever a Fenomenologia como não-natural é também, como é evidente, negar qualquer continuidade linear entre a Filosofia e as ciências naturais.

O ponto de vista de Husserl sobre esta matéria parece ter sido em grande medida partilhado por Heidegger. Numa famosa conferência intitulada Feno- 
menologia e Teologia, escrita em 1927, Heidegger sustentou que, no seio das ciências positivas, se pode falar de diferenças relativas. Uma ciência, por exemplo a Antropologia, investiga uma área específica, outra ciência, como a Biologia, investiga outra área. Entre as ciências positivas e a filosofia fenomenológica há também uma diferença, mas esta diferença não é relativa, mas absoluta. Pois enquanto as ciências positivas são ciências ônticas que estão interessadas nos seres (das Seiende), a Fenomenologia é uma ciência ontológica que se ocupa do Ser (Sein). É neste contexto que Heidegger faz a famosa afirmação de que existem mais semelhanças entre a Teologia e a Química (ambas se ocupam dos seres) do que entre a Teologia e a Filosofia (Heidegger 1978, 49). Dada esta perspectiva, podemos esperar na melhor das hipóteses uma espécie de comunicação unidireccional entre a Filosofia e a Ciência, em que a primeira limita a última.

\section{Filosofia Transcendental e Psicologia Filosófica}

Até à data, a reacção da Fenomenologia ao Naturalismo tem sido bastante inequívoca. Ao contrário do que alguns avançam, não é a defesa clássica do Naturalismo de uma qualquer forma de Materialismo Redutor que constitui o principal obstáculo a uma reconciliação. Não é como se as coisas melhorassem se o Naturalismo optasse por alguma versão de emergentismo ou dualismo de propriedades. O verdadeiro problema tem que ver com o compromisso que o Naturalismo tem com o Cientismo e o Realismo Metafísico. $\mathrm{Na}$ verdade, tendo em conta estes compromissos, a tentativa de naturalizar a Fenomenologia parece fundamentalmente errada. Como explica Husserl ao Neo-Kantiano Rickert numa carta de 1915, ele considerava a luta contra o Naturalismo - uma luta a que dedicou a sua vida - indispensável para o progresso da Filosofia (Husserl 1994, V. 178). Na verdade, para Husserl, um fenomenólogo que adoptasse o Naturalismo teria efectivamente deixado de ser filósofo.

Naturalizar a Fenomenologia pode na realidade - para usar uma formulação empregue pelos editores do volume Naturalizing Phenomenology - ser uma questão de integrar a Fenomenologia num quadro explicativo em que todas as propriedades concebíveis são tornadas contínuas das propriedades admitidas pela ciência natural (Roy et al. 1999, 1-2). No entanto, reavaliemos agora esta definição inicial de naturalização, e consideremos uma proposta algo diferente (e mais modesta). Naturalizar a Fenomenologia pode simplesmente ser uma questão de deixar a Fenomenologia encetar um frutífero intercâmbio e colaboração com as ciências empíricas. A Fenomenologia não estuda os fenómenos que são parte da natureza e por isso estão abertos à investigação empírica, e até onde a Fenomenologia se ocupa de tais fenómenos devia ser informada pelo melhor conhecimento científico disponível. A crença fenomenológica 'nas coisas em si mesmas' apela a que deixemos a 
nossa experiência guiar as nossas teorias. Devíamos prestar atenção à forma como experienciamos a realidade. Os cientistas empíricos podem não prestar muita atenção à estrutura formal da fenomenalidade, mas enquanto investigadores empíricos prestam realmente muita atenção aos fenómenos concretos, pelo que podem estar menos propensos que o filósofo típico a subestimar a riqueza, complexidade e variedade de fenómenos. Como diz Merleau-Ponty em A Natureza:

Como não estar interessado na Ciência para saber o que a Natureza é? Se a Natureza é algo que abrange tudo, não podemos pensar em partir de conceitos, e ainda menos da dedução, devemos antes pensá-la a partir da experiência e, em particular, a experiência na sua forma mais regulada - ou seja, a Ciência (Merleau-Ponty 2000, 87 [trad. modificada]). .

Para pôr as cosias de outra forma, o fim último da Fenomenologia é fornecer uma clarificação fillosófica transcendental, e desse ponto de vista a sua finalidade difere da da ciência empírica. No entanto, a Fenomenologia não se esgota nesta finalidade última. A Fenomenologia fornece também análises detalhadas de vários aspectos da consciência, incluindo a percepção, imaginação, incorporação, ${ }^{2}$ memória, experiência de si, temporalidade, etc. Ao fornecer tais análises, a Fenomenologia aborda questões que são cruciais para compreender a verdadeira complexidade da consciência e pode mesmo fornecer um quadro conceptual para compreender a mente consideravelmente mais valioso que alguns dos modelos actualmente em voga na ciência cognitiva. Mas, pela mesma razão, devia também ser claro que a Fenomenologia se ocupa com temas que partilha com outras disciplinas, e seria errado insistir que ela deveria simplesmente ignorar as descobertas empíricas relativas a esses mesmos temas. Implicará isto que uma descrição fenomenológica da percepção ou da acção deveria necessariamente-ser informada e limitada, por exemplo, pelas investigações dos mecanismos e processos neuronais envolvidos na acção e percepção? Conforme irei defender, em alguns casos as descobertas deste tipo poderiam motivar-nos a lançar um novo olhar sobre a Fenomenologia, para determinar se teríamos acertado da primeira vez, mas de um modo geral uma descrição fenomenológica da percepção e da acção é uma tentativa de fazer justiça à perspectiva da primeira pessoa, procura compreender a experiência em termos do significado que ela tem para o sujeito, e não aborda os mecanismos sub-pessoais que nos permitem experienciar como o fazemos. No entanto, não devemos pôr de parte a ideia de que disciplinas como a Psicopatologia, a Neuropatologia, a Psicologia do Desenvolvimento, a Psicologia Cognitiva, a Antropologia, etc., podem fornecer descrições ao nível da pessoa que podem revestir-se de importância fenomenológica. Os exemplos são inúmeros, mas, para citar só alguns, poderíamos salientar 1) descri- 
ções neuropsicológicas de distúrbios anosognósicos de consciência do corpo, 2) descrições psicopatológicas de distúrbios esquizofrénicos de experiência de si e intencionalidade, 3) descrições do desenvolvimento das interacções sociais na primeira infância, 4) descrições de vários tipos de memória no âmbito da psicologia cognitiva, etc.

Para sermos mais exactos, tomemos como exemplo a escrupulosa análise que Jonathan Cole faz de Ian Waterman que, com 19 anos, devido a uma doença, perdeu qualquer capacidade de tacto e propriocepção do pescoço para baixo; comparemos a análise de Cole desta dramática e incapacitante lesão com a clássica investigação fenomenológica do corpo vivido. Tomemos agora em consideração o trabalho de psiquiatras e psicólogos clínicos como Blankenburg, Parnas and Sass, que nos oferecem meticulosas análises dos distúrbios nas experiências de si e do mundo que se podem encontrar nos doentes esquizofrénicos; comparemo-las com o debate fenomenológico da evidência natural e do reconhecimento de si não-objectificante e pré-reflexivo. Consideremos então o trabalho de psicólogos experimentais como Trevarthen, Stern, Rochat, Reddy and Hobson, e comparemos as suas meticulosas análises das formas primitivas mas fundamentais de entendimento social que se encontram em bebés e crianças pequenas com o trabalho sobre empatia, emparelhamento e intercorporeidade que encontramos em Scheler, Stein, Husserl e Merleau-Ponty. Consideremos finalmente o caso da investigação sobre a memória uma área da investigação que envolve muitas disciplinas diferentes, incluindo a Psicologia Cognitiva, a Neurociência Cognitiva, e a Neuropatologia. Uma das descobertas fundamentais é a de que a memória não é uma única faculdade da mente. É antes composta de uma variedade de processos distintos e dissociáveis. A memória está envolvida quando retemos informação por breves períodos de tempo, quando aprendemos capacidades e adquirimos hábitos, quando reconhecemos objectos quotidianos e quando retemos informação conceptual, e, como é óbvio, a memória está ainda envolvida quando recordamos acontecimentos específicos do passado. Os manuais habitualmente distinguem memória episódica, memória de trabalho, memória de procedimentos e memória semântica, i.e., distinguem a nossa recordação de umas férias de verão passadas, da nossa capacidade de ler e de reter um número de telefone de oito dígitos o tempo suficiente para marcar o número num telefone, da nossa memória de como andar de bicicleta (uma capacidade que adquirimos já há anos), da nossa memória do nome do actual Secretário-geral da ONU (um nome que ouvimos uma vez). Comparemos esta diferenciação - que poderia ser ainda mais refinada incluindo também distinções entre a memória de curto e de longo prazo, ou memória explícita e implícita - com a distinção feita por Husserl entre memória primária e memória secundária, i.e., entre retenção e recordação. Todos estes quatro casos ilustram, diria eu, como as investigações fenomenológicas podem ser enriquecidas de forma produtiva e frutífera pelo facto de terem em conta descobertas empíricas. Poderiam ser dados muitos mais exemplos. 
Por isso nesta proposta, a naturalização da Fenomenologia não consistiria apenas em frisar a utilidade das análises e distinções fenomenológicas para, por exemplo, a Ciência Cognitiva. A questão não seria simplesmente que a Fenomenologia pode vir a provar ser indispensável para obter uma descrição precisa do explanandum - uma condição sine qua non para qualquer tentativa bem conseguida de identificar e localizar o relevante correlato neurobiológico. Não seria apenas uma questão de empregar a visão fenomenológica na investigação empírica da mente. A ideia seria antes que a influência se opera em ambas as direcções, i.e., seria também uma questão de permitir que a fenomenologia aproveitasse das - e se deixasse desafiar pelas - descobertas empíricas. É por isto que é absolutamente apropriado falar de um esclarecimento mútuo (cf. Gallagher 1997).

Estão actualmente em cima da mesa várias propostas complementares, naquilo que diz respeito a rentabilizar esta ideia mais em concreto. Uma proposta intitulada neurofenomenologia foi inicialmente avançada por Varela (1996) e depois desenvolvida por Lutz (2002), Lutz e Thompson (2003), e Thompson (2007). A ideia fundamental era treinar os sujeitos experimentais para que ganhassem maior intimidade com as suas próprias experiências. Através da prática e de uma persistente atenção, os sujeitos experimentais podem aprender a focar a sua atenção em dimensões e aspectos da consciência que não são normalmente considerados, tornando-os assim passíveis de serem descritos de formas mais precisas. Estes dados na primeira pessoa podem então restringir e facilitar a análise e interpretação dos processos neurofisiológicos correlacionados. Ao mesmo tempo, no entanto, levanta-se também a hipótese de que, por exemplo, tomar em consideração descobertas da Neurobiologia e da teoria dinâmica dos sistemas pode ajudar-nos a melhorar e a refinar as análises fenomenológicas clássicas (ver Varela 1997). Como seria isto possível? A ideia básica é muito simples: partamos do princípio que a nossa descrição fenomenológica nos apresenta aquilo que parece ser um fenómeno simples e unificado. Ao estudar os correlatos neuronais deste fenómeno, descobrimos que estão envolvidos dois mecanismos bastante distintos; mecanismos que estão normalmente correlacionados com fenómenos experienciais distintos, por exemplo, a percepção e a memória. Esta descoberta pode motivar-nos a regressar à nossa descrição fenomenológica inicial para verificarmos se o fenómeno em questão é realmente tão simples como pensávamos. Talvez uma análise mais cuidada venha a revelar que ele alberga uma complexidade oculta. No entanto, é muito importante sublinhar que a descoberta de uma complexidade significativa ao nível sub-pessoal - para nos atermos a este exemplo simples - não pode só por si forçar-nos a refinar ou a revier a nossa descrição fenomenológica. Pode apenas servir de motivação para aprofundar a pesquisa. Desta forma, não estamos certamente a sugerir que haja um isomorfismo linear entre o nível sub-pessoal e o pessoal. Em última análise, a única forma de justificar uma afirmação relativa à complexidade ao nível fenomenológico é resolvê-la em termos experienciais. 
Mais recentemente, Gallagher (2003) fez uma proposta ligeiramente diferente, que intitulou fenomenologia de antecipação. ${ }^{3}$ Em vez de se centrar no treino de sujeitos experimentais, a ideia aqui foi partir da concepção experimental, e permitir que descobertas desenvolvidas no âmbito das análises fenomenológicas viessem informar sobre o modo como as experiências são montadas. Para usar um exemplo concreto, consideremos a questão da consciência de si. No âmbito da Psicologia do Desenvolvimento, a chamada tarefa do reconhecimento do reflexo ${ }^{4}$ tem sido por vezes anunciada como o teste decisivo para a consciência de si. Desde os dezoito meses de idade, as crianças adoptam comportamentos autodirigidos quando confrontadas com a sua imagem-reflexo, e tem sido defendido que a consciência de si só está presente a partir do momento em que a criança é capaz de se reconhecer ao espelho (cf. Lewis 2003). Escusado será dizer que esta linha de pensamento faz uso de uma noção muito particular de consciência de si. Em vę de nos limitarmos a deixar que as descobertas da fenomenologia guiem a nossa interpretação dos resultados obtidos através do teste do reconhecimento do reflexo, uma possibilidade seria deixar que a explicação e análises fenomenológicas da autoconsciência pré-reflexiva guiassem a nossa concepção do paradigma experimental. Desta forma já não envolveria o teste do reconhecimento do reflexo - que os fenomenólogos tenderiam geralmente para considerar como prova da presença de uma forma de consciência de si bastante sofisticada - mas, por exemplo, tentar identificar a presença de formas bastante mais primitivas de consciência proprioceptiva do corpo. Para a fenomenologia de antecipação, no entanto, não implica que se pressuponha ou se aceite simplesmente resultados fenomenológicos bem ensaiados. Pelo contrário, implica testar esses resultados e, de uma forma mais abrangente, incorporar um movimento dialéctico entre descobertas anteriores conquistadas pela Fenomenologia e experiências preliminares que virão a especificar ou alargar estas descobertas para efeitos de uma experiência ou investigação empírica particulares (Gallagher 2003).

Existem precedentes na Fenomenologia clássica para tais abordagens integrativas? Consideremos brevemente e comparemos os casos de Husserl e de Merleau-Ponty, respectivamente. Em muitas das suas obras, Husserl distingue duas diferentes abordagens fenomenológicas da consciência. Por um lado, temos a Fenomenologia Transcendental, e por outro, temos aquilo a que ele chama Psicologia Fenomenológica (Husserl 1977). Qual a diferença entre estas duas abordagens? Ambas se ocupam da consciência, mas fazem-no com objectivos diferentes. Para Husserl, a tarefa da Psicologia Fenomenológica é investigar a consciência intencional de uma forma não redutiva, ou seja, de uma forma que respeite a sua peculiaridade e características distintivas. A Psicologia Fenomenológica é uma forma de Psicologia Filosófica que leva a 
sério a perspectiva da primeira pessoa mas que - em contraste com a Fenomenologia Transcendental - se mantém no âmbito da atitude natural. A diferença entre as duas é consequentemente que a Psicologia Fenomenológica pode ser descrita como uma análise regional-ontológica que investiga a consciência pela consciência. Por ouțro lado, a Fenomenologia Transcendental é um empreendimento global muito mais ambicioso. Está interessada na dimensão constitutiva da subjectividade, ou seja, está interessada numa investigação da consciência na medida em que a consciência é considerada uma condição de possibilidade do sentido, da verdade, da validade e da aparição.

Qual é a relevância desta distinção? Embora o objectivo principal de Husserl seja o desenvolvimento da Fenomenologia Transcendental, ele não ignorava o facto de que as suas análises pudessem ter ramificações para e ter pertinência para o estudo psicológico da consciência, e vice-versa. Como escreveu Husserl: "todas as análises e teorias da Fenomenologia Transcendental - incluindo [...] a teoria da constituição transcendental de um mundo objectivo - podem ser levadas a cabo no mundo natural, a partir do momento em que pomos de parte a atitude transcendental. Em termos eidéticos e empíricos, uma Psicologia pura - uma Psicologia que meramente explica o que pertence à psique, a um Ego humano concreto, como a sua própria essência intencional - corresponde a uma Fenomenologia Transcendental, e vice-versa." (Husserl 1999, 131). Husserl falava, consequentemente, de um paralelismo entre a Psicologia Fenomenológica e a Fenomenologia Transcendental, e defendia que é possível passar de uma para a outra através de uma mudança de atitude. $\mathrm{Na}$ verdade, nas Meditações Cartesianas ele chega a escrever que é inútil tratar separadamente a Fenomenologia Transcendental e a ciência positiva da Psicologia Intencional. A princípio, ele sugere que a primeira deveria preparar o caminho, e que a última poderia então apropriar-se de alguns dos resultados (sem ter de se incomodar com as considerações transcendentais), mas como ele acaba por dizer mais à frente, no seu âmago a Psicologia Intencional (o estudo da consciência) contém uma dimensão transcendental, faz parte da Filosofia Transcendental, embora este facto vá permanecer oculto até que a Psicologia venha a ser liberada da sua ingenuidade (Husserl 1999, 147). Poderão tais considerações permitir a possibilidade de que descobertas empíricas (se baseadas numa análise meticulosa dos fenómenos e desde que sujeitas às modificações necessárias) sejam adoptadas e, consequentemente, venham a influenciar ou condicionar a análise da subjectividade transcendental? Não vejo porque não. Consideremos por exemplo a análise levada a cabo por Husserl em Ideias II sobre os efeitos do consumo da droga antelmíntica santonina (Husserl 1989, 67-69), ou para escolhermos um exemplo mais fundamental, consideremos o facto de que o caminho ontológico de Husserl para a redução toma uma cuidadosa descrição de uma região ontológica específica como directriz para a subsequente análise transcendental (Husserl 1970, 170-174).

Se avançarmos para Merleau-Ponty, é bem conhecido que, já na sua primeira grande obra $A$ Estrutura do Comportamento, cita autores tão diversos 
como Pavlov, Freud, Koffka, Piaget, Watson, e Wallon. O último subcapítulo do livro tem o título "Não Existe Uma Verdade no Naturalismo?". Contém uma crítica à Filosofia Transcendental de Kant, e, na última página do livro, Merleau-Ponty apela a uma redefinição da Filosofia Transcendental que a faça ter em conta o mundo real (Merleau-Ponty 1963, 224). Assim, em vez de nos fazer escolher entre uma explicação científica externa ou uma reflexão fenomenológica interna, uma escolha que iria dilacerar a relação viva entre a consciência e a Natureza, Merleau-Ponty pede-nos para reconsiderarmos a própria oposição, e procurarmos uma dimensão que esteja para além quer do objectivismo quer do subjectivismo.

Este interesse na ciência positiva, no seu significado para a Fenomenologia, mantém-se em destaque também em muitas das obras posteriores de Merleau-Ponty. O seu uso da Neuropatologia (o famoso caso Schneider de Gelb e Goldstein) na Fenomenologia da Percepção é muito conhecido. Por algum tempo nos anos de 1949-1952, Merleau-Ponty chegou mesmo a leccionar uma cadeira de Psicologia Infantil na Sorbonne. No que diz respeito às suas últimas obras, podemos encontrar uma afirmação significativa em Signos, onde Merleau-Ponty declara que "a tarefa última da Fenomenologia enquanto Filosofia da Consciência é compreender a sua relação com a não-fenomenologia. Aquilo que dentro de nós resiste à Fenomenologia - ser natural, a fonte 'bárbara' de que falava Schelling - não pode ficar de fora da Fenomenologia e deve ter o seu lugar dentro dela" (Merleau-Ponty 1964, 178).

O que é interessante e relevante é que Merleau-Ponty não concebeu a relação entre a Fenomenologia Transcendental e as ciências empíricas como uma questão de como aplicar descobertas fenomenológicas já consolidadas a questões empíricas. Não era simplesmente uma questão de como a Fenomenologia poderia limitar as ciências positivas. Pelo contrário, a ideia de Merleau-Ponty era que a própria Fenomenologia pode ser alterada e modificada através do seu diálogo com as disciplinas empíricas. Com efeito, ela precisa deste confronto se quer desenvolver-se correctamente. E atenção que Merleau-Ponty defendeu este ponto de vista sem com isso reduzir a Fenomenologia a apenas mais uma ciência empírica, sem por isso a despojar da sua natureza filosófica transcendental (Merleau-Ponty 1962, 63).

Para clarificar o carácter distintivo desta posição quanto à relação entre a Filosofia a ciência empírica, permitam-me que estabeleça uma breve comparação com a posição recentemente defendida por Bennett e Hacker no seu livro The Philosophical Foundations of Neuroscience. De acordo com o seu ponto de vista, uma investigação filosófica da consciência difere, em princípio, de uma empírica pela razão de que não tem qualquer significado sugerir que a última pode disputar ou mesmo tomar o lugar da primeira. A Filosofia não se ocupa de assuntos relacionados com factos, mas de assuntos relacionados com significados. O ofício da Filosofia tem que ver com possibilidades lógicas, não com factos empíricos. A sua área não é o domínio da verdade ou falsidade empíricas, mas o domínio do sentido e do absurdo. Para pôr as 
coisas noutros termos, a Filosofia clarifica o que faz e o que não faz sentido. Investiga e descreve os limites do sentido: ou seja, os limites daquilo que pode ser pensado e dito de modo coerente. A fronteira entre o que faz e o que não faz sentido, entre o que tem significado e aquilo que ultrapassa os limites do sentido, é determinada pelos conceitos que usamos, e o modo como a Filosofia pode contribuir para uma investigação sobre a natureza da mente é, por conseguinte, a clarificação do nosso conceito de mente e a forma como este conceito está ligado a outros conceitos com ele relacionados (Bennett \& Hacker 2003, 399, 402). O método básico para dissolver perplexidades conceptuais consiste em examinar cuidadosamente e descrever o uso das palavras - i.e., devemos investigar aquilo que os falantes competentes, usando as palavras de forma correcta, dizem e não dizem. Em vez de nos empenharmos em afirmações de primeira ordem sobre a natureza das coisas (coisa que podemos deixar ao cuidado de várias disciplinas científicas), a Filosofia deve, por conseguinte, ocupar-se com os pré-requisitos conceptuais de todo o exame científico. As questões conceptuais antecedem as questões de verdade ou falsidade. Elas são pressupostas por qualquer investigação científica, e qualquer falta de clareza no que diz respeito aos conceitos relevantes reflectir-se-á numa correspondente falta de clareza nas questões formuladas, e consequentemente na concepção das experiências que pretenderem dar-lhes resposta (Bennett \& Hacker 2003, 2). Para pôr as coisas em termos mais directos, a investigação empírica que se desenvolve a partir de premissas conceptualmente defeituosas irá provavelmente produzir questões e respostas empíricas incoerentes. Bennett e Hacker prosseguem então argumentando que a relação entre as questões conceptuais e empíricas é unidireccional, e que a Filosofia tem muito mais importância para a Ciência do que o contrário. Pois enquanto os filósofos podem clarificar os conceitos usados na Ciência e prestar assim um enorme serviço à Ciência, é um erro pensar que a Ciência poderia ter grande impacto na Filosofia. Com efeito, Bennett e Hacker consideram até ridíçula a suposição de que as provas científicas possam contrariar uma análise filosófica (Bennett \& Hacker 2003, 404). Do seu ponto de vista, não devemos cometer o erro de confundir teorias metafísicas ou epistemológicas com afirmações empíricas que podem ser corroboradas por um experimentum crucis. Assim, a relação entre a Filosofia e a ciência empírica é um empreendimento unilateral. É uma aplicação de conceitos pré-fabricados. Não existe reciprocidade, e não há feedback. A aplicação não leva a uma modificação da análise original.

Este é certamente um tipo de reacção ao desafio colocado à Filosofia pela revitalização do Naturalismo. Mas tal como sugeri, não considero que seja esta a forma como a Fenomenologia reagiu ou deve reagir. Permitir que uma análise do uso comum da linguagem seja o nosso principal, senão mesmo o único, guia para uma investigação fillosófica da mente, é demasiado restritivo e subestima a importância que a linguagem comum efectivamente tem na metafísica do senso comum. Impede a análise fenomenológica concreta que poderia vir a revelar aspectos e dimensões da mente que não estão sim- 
plesmente acessíveis a qualquer reflexão sobre o senso comum (pensemos, por exemplo, nas investigações de Husserl sobre as estruturas da consciência temporal ou da consciência pictórica) e que ao mesmo tempo podem ser questionadas e enriquecidas por descrições fornecidas pela ciência empírica. Em contraste, talvez não seja totalmente sem razão que o estilo de Filosofia Analítica defendido por Bennett e Hacker tenha sido acusado de promover uma certa inércia semântica e conservadorismo conceptual.

Os dados empíricos podem servir para questionar e para corroborar análises teóricas. Inversamente, as análises conceptuais podem fornecer aos cientistas empíricos direcções e ferramentas e podem ainda ajudar na concepção e desenvolvimento de paradigmas experimentais. No entanto, embora as descobertas empíricas sejam importantes, é obvio que não podemos esquecer que estão abertas à interpretação. A sua interpretação dependerá geralmente do quadro em que cada um opera. Portanto, o impacto teórico de um caso empírico não é necessariamente algo que possa ser facilmente determinado. Muito embora eu seja da opinião que a Fenomenologia deveria prestar atenção às descobertas empíricas, isto não implica que devesse necessariamente aceitar também as interpretações (metafísicas e epistemológicas) que a Ciência faz destas descobertas.

É importante encorajar o intercâmbio entre a Fenomenologia e a ciência empírica, mas a possibilidade de uma cooperação frutífera entre as duas não deve fazer-nos negar a diferença que existe entre ambas. Não vejo qualquer incoerência em afirmar que a Fenomenologia deve ser informada pelo melhor conhecimento científico disponível, e insistir, ao mesmo tempo, que as preocupações decisivas da Fenomenologia são filosóficas transcendentais e que a Filosofia Transcendental difere da ciência empírica.

\section{Naturalismo Filosófico}

Até ao momento, distingui duas interpretações diferentes da naturalização:

- A primeira proposta radical vê a naturalização da Fenomenologia como algo que acabará por tornar a Fenomenologia uma parte, ou pelo menos uma extensão das Ciências Naturais, e argumenta que este é um objectivo que devemos tentar alcançar. Conforme deixei já claro, considero esta sugestão desajustada, uma vez que nega de facto a legitimidade dos métodos e questões que são exclusivos da Filosofia. Quer substituir a clarificação transcendental que a Fenomenologia oferece por um relato explicativo. Caso viéssemos a implementar esta estratégia, estaríamos ao mesmo tempo a abandonar muito daquilo que torna a Fenomenologia filosoficamente interessante. A Fenomenologia é fundamentalmente, insisto, um esforço filosófico transcendental, e 
embora se possa facilitar a sua naturalização através do abandono da dimensão transcendental, não seria possível dessa forma conservar aquilo que faz da Fenomenologia uma disciplina, uma estratégia e um método filosóficos distintos.

- A segunda proposta, mais modesta, sustenta que uma Fenomenologia naturalizada é o tipo de Fenomenologia que empreende com a ciência empírica um intercâmbio produtivo e pleno de significado. A Fenomenologia pode questionar e elucidar assunções teóricas básicas feitas pela ciência empírica, assim como pode prestar apoio no desenvolvimento de novos paradigmas experimentais. A ciência empírica pode colocar a Fenomenologia perante descobertas concretas que esta não pode simplesmente ignorar, devendo antes ser capaz de acomodar; perante provas que podem forçá-la a refinar ou a rever as suas próprias análises.

Nesta altura, no entanto, é necessário abordar brevemente um assunto que até agora tem ficado como que em segundo plano. Poderia argumentar-se que o Naturalismo está longe de ser um termo unívoco, e que a verdadeira tarefa que a Fenomenologia tem perante si é resistir à tentativa, por parte dos realistas metafísicos, de monopolizar o conceito de Natureza. O verdadeiro desafio seria, por outras palavras, repensar o próprío conceito de Natureza - um conceito sobre o qual Hume declarou "não há nenhum outro mais ambíguo e equívoco" (Hume 1888, 474). Em suma, porquê aceitar uma concepção da Natureza indevidamente restrita, porque não reconhecer que pode haver outros tipos de Naturalismo para além daquele que dá por adquirido que a Natureza se esgota naquilo que as Ciências Naturais - da forma que são actualmente consideradas - podem revelar-nos (cf. McDowell 1996). Para pôr as coisas de outra forma, talvez devêssemos compreender que é imperativo operar com uma noção de Natureza mais rica, e que tenha espaço para questões como as do significado, contexto, perspectivas, capacidades e sedimentos culturais.

No seu livro mais recente, Mind in Life, esta proposta foi adoptada por Evan Thompson, que sustenta que uma naturalização da Fenomenologia conduziria a uma renovada compreensão da natureza tanto da vida como da mente (p. 14). Com efeito, do seu ponto de vista, a Fenomenologia fornece uma forma de observar e descrever os fenómenos naturais que trazem a lume características que, de outra forma, permaneceriam invisíveis para a Ciência; características como a ipseidade, a normatividade, subjectividade, intencionalidade e temporalidade. Assim, uma das ambições decisivas de Mind in Life é precisamente mostrar como pode a Fenomenologia tornar-nos capazes de valorizar a vida interior dos sistemas biológicos (p. 358).

Um conceito fulcral na análise de Thompson é o conceito de auto-organização ou autopoiesis. Thompson sustenta que os organismos vivos têm 
uma forma de individualidade e unidade diferentes e emergentes em relação ao ser físico. Mesmo ao nível metabólico, os organismos vivos preservam a sua identidade através de alterações materiais e, nesse sentido, pode falar-se da sua auto-identidade em termos de um padrão dinâmico invariável (p. 75). Como diz Thompson, existir enquanto indivíduo significa não só ser numericamente distinto dos outros seres, mas também ser um pólo do eu numa relação dinâmica com aquilo que é outro (p. 153). Mesmo ao mínimo nível celular, os organismos vivos preservam as suas identidades diferenciando-se em relação ao meio circundante (p. 149). Thompson sublinha que esta diferenciação entre o eu e o mundo, esta fronteira entre dentro e fora, não deve ser confundida com independência ou separação. A identidade e individualidade do organismo é algo que se estabelece em constante troca com, assimilação do, e adaptação ao mundo (p. 150).

$\mathrm{Na}$ medida em que o organismo se auto-organiza, as coisas têm significado ou valência para ele, e isto significa que ele, na qualidade de ser vivo, não é uma pura exterioridade, mas encarna antes uma certa interioridade. Mesmo ao nível bacteriano, é consequentemente possível distinguir uma entidade interna de um mundo exterior. Esta interioridade da vida é um precursor da interioridade da consciência (a qual deve ser vista como uma estrutura de ligação com o mundo). A vida e a mente partilham uma série de propriedades organizacionais básicas. As propriedades distintivas da mente são uma versão enriquecida daquelas que são fundamentais à vida. A mente é como a vida e a vida é como a mente (p. 128). Portanto, a ideia geral de Thompson é que, ao articular uma concepção da cognição de base biológica que atribui um lugar natural ao significado que as coisas têm para um organismo, se pode fazer a ponte entre a subjectividade e a Fenomenologia, onde outras teorias se deparam com um hiato explicativo.

Num passo que evoca as primeiras obras de Merleau-Ponty, Thompson rejeita o objectivismo e vê o seu próprio projecto como um projecto que respeita o estatuto transcendental da consciência. Para a Fenomenologia, a objectividade não é algo de pré-existente, mas algo que se constitui, e Thompson afirma explicitamente que esta descoberta fundamental é partilhada pela sua abordagem enactiva. De acordo com esta última posição, a cognição não é uma representação fiel que ocorre entre duas entidades separadas e independentes, mente e mundo. Pelo contrário, a cognição é vista não como algo dentro do cérebro ou dentro do corpo, mas como algo que atravessa a clivagem entre corpo, cérebro, e ambiente. Em vez de ver o mundo do ser cognitivo como um reino externo que é representado (espelhado) internamente no cérebro, a abordagem enactiva vê-o como um domínio cognitivo que é enactivo, i.e., que é trazido ou constituído pela relação do organismo vivo com o seu ambiente (p. 154).

Dado aquilo que se disse até agora, não deverá ser surpresa que Thompson defenda que não temos hipótese de unir mente e Natureza a menos que redefinamos ambos os termos e passemos a ver a consciência como fundamentalmente incorporada. Em vez de considerar que o desafio consiste em explicar 
como pode a consciência surgir em objectos inanimados, uma abordagem mais significativa e mais útil seria examinar a relação entre um corpo vivo e um corpo vivido (com mente) (p. 237). Portanto, em vez de se enquadrar o problema da consciência em termos do problema mente-corpo, Thompson sugere que o concebamos antes como um problema corpo-corpo.

De acordo com a proposta presentemente em discussão, uma naturalização da Fenomenologia implicaria uma reavaliação do conceito habitual de naturalização e uma revisão da clássica dicotomia entre o empírico e o transcendental. Em suma, de acordo com a presente proposta, uma naturalização da Fenomenologia poderia implicar não só uma modificação radical (e não abandono) da Filosofia Transcendental, mas também um repensar do conceito de Natureza - um repensar que poderia em última análise levar a uma transformação das próprias ciências naturais. Independentemente do quanto uma tal proposta pode parecer, do ponto de vista teórico, fascinante, deverá, no entanto, ser óbvio que a tarefa é intimidatória e de que há ainda um longo caminho a percorrer.

Deve, no entanto, dizer-se que há quem argumente que ainda estão para ser totalmente compreendidas todas as implicações teóricas das revoluções levadas a cabo por Einstein e por Bohr no campo da Física. Em 1922, Moritz Schlick deu uma palestra em que defendeu que a teoria geral da relatividade tinha infirmado a Filosofia Transcendental e vingado a Filosofia Empirista. Esta opinião encontrou bastante eco, mas como sustentou Ryckman no seu recente livro The Reign of Relativity: Philosophy in Physics 1915-1925, está bastante incorrecta. Como sublinha Ryckman, o notável matemático Herman Weyl, que era um dos colegas de Einstein em Zurique, e que contribuiu decisivamente para a interpretação e ulterior desenvolvimento tanto da teoria geral da relatividade quanto do campo da mecânica quântica, não só bebeu muitíssimo da crítica de Husserl ao Naturalismo, mas foi também profundamente influenciado pelo Idealismo Transcendental de Husserl. Assim, não é de forma nenhuma óbvio que alguns dos desenvolvimentos decisivos na física teórica deixem realmente intocados as nossas concepções habituais de subjectividade, objectividade e conhecimento.

Uma forma mais modesta e consideravelmente mais fácil de abordar a questão atinente à relação entre a Fenomenologia e o Naturalismo é ver concretamente como podem a Fenomenologia e as Ciências Empíricas empreender um intercâmbio frutífero e com significado. Não é coincidência que Husserl tenha fama de ter pedido trocos (Kleingeld) aos alunos, e que numa carta a Natorp tenha escrito que permanecia insatisfeito "enquanto as grandes notas não tivessem sido trocadas por miúdos" (Husserl 1994, V. 56). Husserl sublinhou a importância de apresentar análises minuciosas e cuidadosas à custa do desenvolvimento de sistemas ambiciosos e especulativos. Deveríamos aceitar este conselho. Claro que, como em tantos outros casos, a prova do pudim está em comê-lo, e quaisquer afirmações relativas a um mútuo esclarecimento entre a Fenomenologia e a ciência empírica devem ser demonstradas in concreto. 


\section{Referências}

Aikin, S. F. (2006). "Pragmatism, Naturalism, and Phenomenology." Human Studies 29, 317-340.

Bennett, M. R., Hacker, P. M. S. (2003). Philosophical Foundations of Neuroscience. Oxford: Blackwell.

Crick, F. (1995). The astonishing hypothesis. London: Touchstone.

Gallagher, S. (1997). "Mutual Enlightenment: Recent Phenomenology in Cognitive Science." Journal of Consciousness Studies 4/3, 195-214

Gallagher, S. (2003). "Phenomenology and experimental design," Journal of Consciousness Studies 10/9-10, 85-99.

Heidegger, M. (1978). Wegmarken. Frankfurt am Main: Vittorio Klostermann.

Hume, D. (1888). A Treatise of Human Nature. Oxford: Clarendon Press.

Husserl, E. (1970). The Crisis of European Sciences and Transcendental Phenomenology. An Introduction to Phenomenology, trans. D. Carr. Evanston, IL: Northwestern University Press.

Husserl, E. (1977). Phenomenological Psychology: Lectures, Summer Semester, 1925, trans. J. Scanlon. The Hague: Martinus Nijhoff.

Husserl, E. (1982). Ideas Pertaining to a Pure Phenomenology and to a Phenomenological Philosophy. First Book. General Introduction to a Pure Phenomenology. trans. F. Kersten. The Hague; Martinus Nijhoff, 1982.

Husserl, E. (1984). Einleitung in die Logik und Erkenntnistheorie. Vorlesungen 1906/07. Husserliana XXIV. Dordrecht: Martinus Nijhoff.

Husserl, E. (1987). Aufsätze und Vorträge (1911-1921). Husserliana XXV. Dordrecht, Martinus Nijhoff.

Husserl, E. (1989). Ideas Pertaining to a Pure Phenomenology and to a Phenomenological Philosophy. Second Book. Studies in the Phenomenology of Constitution, transl. R. Rojcewicz and A. Schuwer. Dordrecht: Kluwer Academic Publishers.

Husserl, E. (1994). Briefwechsel, Husserliana Dokumente III/1-10, Kluwer Academic Publishers, Dordrecht.

Husserl, E. (1999). Cartesian Meditations: An Introduction to Phenomenology, trans. D. Cairns. The Hague: Martinus Nijhoff.

Husserl, E. (2001). Logical Investigations I-II, trans. J. N. Findlay. London: Routledge.

Lewis, M. (2003). "The Development of Self-Consciousness." In J. Roessler \& N. Eilan (eds.): Agency and Self-awareness (Oxford: Oxford University Press), pp. 275-295.

Lutz, A. (2002). "Toward a neurophenomenology as an account of generative passages: A first empirical case study." Phenomenology and the Cognitive Sciences 1, 133-67.

Lutz, A. and Thompson, E. (2003). "Neurophenomenology: Integrating subjective experience and brain dynamics in the neuroscience of consciousness." Journal of Consciousness Studies 10, 31-52. 
McDowell, J. (1996). "Two sorts of naturalism." In R. Hursthouse, G. Lawrence, W. Quinn (eds.): Virtues and Reasons: Philippa Foot and Moral Theory (Clarendon Press, Oxford), pp. 149-179.

Merleau-Ponty, M. (1962). Phenomenology of Perception. Trans. C. Smith. London: Routledge \& Kegan Paul.

Merleau-Ponty, M. (1963). The Structure of Behavior, trans. A. L. Fisher. Pittsburgh: Duquesne University Press.

Merleau-Ponty, M. (1964). Signs. Trans. R. C. McCleary. Evanston, IL: Northwestern University Press.

Merleau-Ponty, M. (2000). Nature: Course Notes from the Collège de France. Evanston: Northwestern University Press.

Roy, J.-M., Petitot, J., Pachoud, B., and Varela, F. J. (1999). "Beyond the Gap: An Introduction to Naturalizing Phenomenology." In J. Petitot, F. J. Varela, B. Pachoud, and J.-M. Roy (eds.), Naturalizing Phenomenology, Stanford: Stanford University Press, pp. 1-83.

Ryckman, T. (2005). The Reign of Relativity: Philosophy in Physics 1915-1925. New York: Oxford University Press.

Sellars, W. (1963). Science, Perception and Reality. London: Routledge and Kegan Paul.

Thompson, E. (2007). Mind in Life: Biology, Phenomenology, and the Sciences of Mind. Cambridge, MA: Harvard University Press.

Varela, F. (1996). "Neurophenomenology: A Methodological Remedy to the Hard Problem." Journal of Consciousness Studies 3, 330-50.

Varela, F. (1997). "The Naturalization of Phenomenology as the Transcendence of Nature. Searching for generative mutual constraints." Alter 5, 355-381.

Williams, B. (2005). Descartes: The Project of Pure Enquiry. London: Routledge.

\section{ABSTRACT}

Whereas 20 or 30 years ago one might have been inclined to characterize the development of 20th century philosophy in terms of a linguistic turn, a turn from a philosophy of subjectivity to a philosophy of language, it might today be more apt to describe the development in terms of a turn from anti-naturalism to naturalism. But insofar as naturalists consider the scientific account of reality authoritative, a commitment to naturalism is bound to put pressure on the idea that philosophy can make a distinct and autonomous contribution to the study of reality. In the following, I will discuss the question of how phenomenology ought to respond to this challenge. What sense can we make of recent proposals to naturalize phenomenology? 
